\title{
Oxidative Stress and Diseases: Current Topics and Perspective with Clinical Application in Japan
}

Eiichiro Ichiishi*, Takaaki Ohtake, Kiichi Satoh, and Yutaka Kohgo

Department of Medicine, International University of Health and Welfare Hospital, Japan

\begin{abstract}
Evaluation of oxidative stress and diseases have markedly progressed and developed in basic science, and various trials of prevention and treatment have recently been performed at clinical levels, making remarkable progress in medical practical field. This report will introduce recent topics in Japan and other countries and review Japanese reports of oxidative stress pathways and development of healthy products, current topics and problems with molecular hydrogen, oxidative stress markers attracting attention at clinical practices, recent knowledge on oxidative stress and the immune system, and new development in regenerative medical treatment. A problem with the above development in clinical fields and application of oxidative stress is that health foods and beverages allegedly effective for reducing oxidative stress are already on the market but there are more than a few of them have a poor scientific evidence and their effects are questionable. Unquestionable bases and evidence of 'oxidative stress and diseases' have already accumulated in basic medicine. I hope these will be actively applied in clinical fields, accumulate evidence by performing systematic clinical studies and trials, and actually facilitate health promotion, disease prevention, and treatment effects in humans, making great contributions at actual medical practical care.
\end{abstract}

Keywords: Clinical application; Oxidative stress; Reactive oxygen species

\section{Introduction}

In recent studies, involvement of oxidative stress is considered a cause of pathogenesis of various diseases, such as aging, carcinogenesis, arteriosclerosis, myocardial infraction, Alzheimer's disease, and Parkinson's disease. Substances removing reactive oxygen species produced in the body include antioxidative substances which directly react with reactive oxygen species, such as vitamins $\mathrm{C}$ and $\mathrm{E}$ and polyphenol, and endogenous antioxidative enzymes such as glutathione peroxidase and catalase [1].

Reactive oxygen species damage tissue, cells, and genes, and oxidative stress is produced to balance protective factors against these damages. Various attempts of its prevention and treatment have been performed at the clinical level and a marked progress has been made in this field.

However, although antioxidative substances can be orally ingested, they are predicted to be difficult to maintain at a high concentration in the body because they are degraded and consumed. In contrast, antioxidative enzymes act as catalysts and are not consumed in the body, but, being proteins, they are difficult to ingest orally [1].

Substances and enzymes actually applied clinically to diagnose, prevent, and treat oxidative stress at the human level under these circumstances, and several recent topics which are about to be clinically applied will be picked up and their current state and problems will be considered.

Pathways of antioxidative systems, mainly the Nrf2-ARE pathway, have recently been elucidated at the cell level, and studies on food and drug development are progressing [2]. The current state of and problems with hydrogen, which has been attracting attention in the beverage development, will also be mentioned [3].

Evaluation is difficult when measurement is difficult. Topics about oxidative stress markers in the current clinical application will also be covered in the current review [4].
With progression of elucidation at the cell level, the importance of oxidative stress and antioxidative components in the role and function of immune cells has been pointed out [5]. Thus, we paid attention to granulocytes among immune cells in a pilot study, and suggested a possibility that reactive oxygen measurement of granulocytes collected from patients leads to preventive medicine and molecular diagnosis [6].

In this review, recent topics in Japan will be mainly introduced with regard to the current state of and problems with clinical application of oxidative stress. The application for diagnosis, treatment, and prevention at bedside in hospitals, preventive medicine, and home health care is expected.

\section{Discovery Of Nrf2-ARE Pathway Activators in Food and Possibility of its Clinical Application}

The Nrf2-ARE pathway is known as an endogenous antioxidative system inducing antioxidative enzyme expression. A transcription factor, Nrf2, transfers into the nucleus when it is exposed to oxidative stress and binds to antioxidant response elements (ARE) present in the promoter field, through which it induces antioxidative enzyme expression (Figure 1). If this Arf2-ARE pathway can be activated by a low-molecular-weight compound, it may be useful protection against oxidative stress, and its research and development are progressing in the food and drug fields.

In epidemiological surveys, ingestion of fruits and vegetables is

*Corresponding author: Eiichiro Ichiishi, MD, PhD, Department of Medicine, International University of Health and Welfare Hospital, 537 Iguchi, Nasusihobara-city, Tochigi pref. 329-2763, Japan, Tel: +81-22-795-5261; Fax: +81-22-795-5261; E-mail: ichiishi@xg7.so-net.ne.jp

Received October 12, 2016; Accepted October 26, 2016; Published October 27 2016

Citation: Ichiishi E, Ohtake T, Satoh K, Kohgo Y (2016) Oxidative Stress and Diseases: Current Topics and Perspective with Clinical Application in Japan. Aging Sci 4: 161. doi: 10.4172/2329-8847.1000161

Copyright: @ 2016 Ichiishi E, et al. This is an open-access article distributed under the terms of the Creative Commons Attribution License, which permits unrestricted use, distribution, and reproduction in any medium, provided the original author and source are credited. 


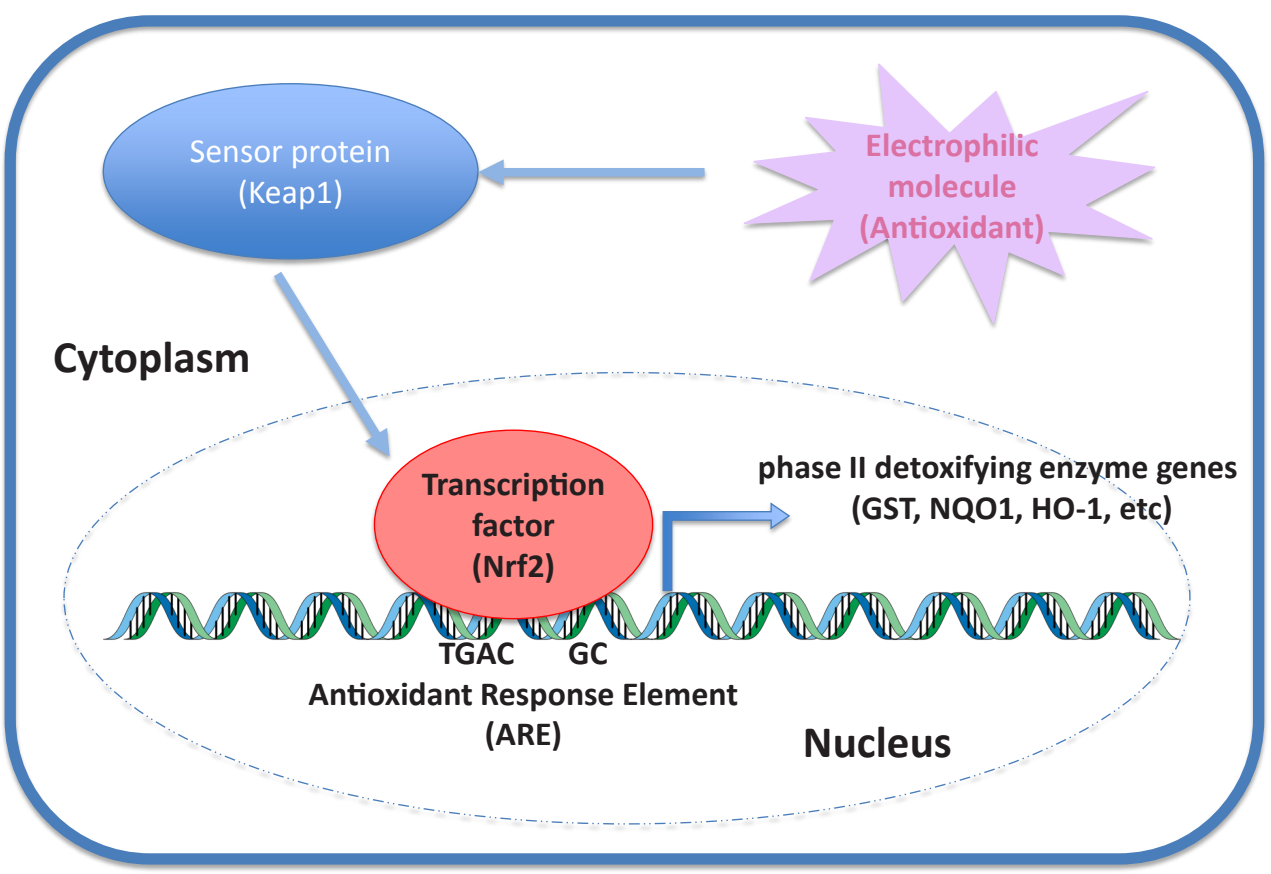

Figure 1: The expression system of oxidative stress defense enzymes via Nrf2 by antioxidants [12].

expected to be effective to prevent various diseases involving oxidative stress in humans. Antioxidative substances contained in fruits and vegetables are attracting attention as a mechanism [7], but there is only a little knowledge about induction of antioxidative enzymes. Thus, studies in which novel Nrf2-ARE pathway-activating components were identified in familiar food are introduced below [8].

When the Nrf2-ARE pathway-activating action was compared among diethyl ether extracts of fruit juice samples (peach, apple, strawberry, cranberry, raspberry, and mandarin orange) and vegetable samples (green perilla, Jew's marrow, crown daisy, celery, parsley, and red perilla) the green perilla extract strongly activated the Nrf2-ARE pathway. When the active component in the green perilla extract was purified and isolated using reverse-phase HPLC, followed by structural analysis using nuclear magnetic resonance and mass spectrometry, the structure of the active component was identified as 2,3'-dihydroxy4',6'-dimethoxychalcone (DDC) [8].

Chemically synthesized DDC exhibited cytoprotection by increasing antioxidative enzymes through activating the Nrf2-ARE pathway. It was not previously known that DDC is contained in green perilla, and its pharmacological action has also not previously been reported [8].

A synthetic triterpenoid, CDDO-methyl ester, has been reported to exhibit antioxidative anti-inflammatory action through activating the Nrf2-ARE pathway at a low concentration [9]. This CDDO-methylester was effective for NIDDM patients with chronic nephropathy in a phase II study [10], suggesting its applicability as a low-molecularweight activator of the Nrf2-ARE pathway [11].

Other substances targeting the Nrf2-ARE or other pathways and attracting attention include a chemical sensor, Keap1, and this is known to interact with Nrf2 described above [12]. As compounds which interact with Keap1 and induce Nrf2, sulforaphane [13] contained in broccoli sprout, the pungent component of wasabi (allyl isothiocyanate [14]),
A<smiles></smiles>

C<smiles>O=c1c(O)c(-c2ccc(O)c(O)c2)oc2cc(O)cc(O)c12</smiles>

D<smiles>CC(C)c1cc2c(c(O)c1O)C1CCCC(C)(C)C1CCC21OCCO1</smiles><smiles>CCC/C=C/C=C1/C(=O)C=C[C@@H]1C/C=C\CCCC(=O)O</smiles>

E<smiles>Nc1nc2c(nc([N+](=O)[O-])n2C2OC3COP(=O)([O-])O[C@H]3[C@H]2O)c(=O)[nH]1</smiles><smiles>COc1cc(O)c(CC=C(C)C)c(O)c1C(=O)/C=C/c1ccc(O)cc1</smiles>

Figure 2: Various electrophilic molecules A. Sulforaphane, B.Carnosol, C.Quercetin, D.Prostaglandin J2, E.8-nitro-cGMP, F.Xanthohumol [12].

carnosol [13] contained in rosemary, and quercetin [15] contained in onion and buckwheat have been reported. Prostaglandin J2 [16] and 8-nitro-cGMP [17] are reported to activate Arf2 and Xanthohumol [18] are known to be ARE derivative agent. These components (Figure 2) will increasingly attract attention as compounds capable of controlling 
oxidative stress in cells at the transcription factor level with regard to evidence and clinical application in healthy product development.

\section{Medical Gas and Clinical Application: Possibility of Molecular Hydrogen}

Medical gas is a generic name of gas molecules with pharmacological kinetics used for treatment and diagnosis in the medical field. A new research field termed gas biology has recently been proposed, in which biological control mechanisms mediated by gas molecules are elucidated, and studies on receptors, metabolism, and physiological and pathological actions are progressing, but many fields have not yet been elucidated.

Biogases attracting attention for their role in biological signal transmission include nitric monoxide $(\mathrm{NO})$, hydrogen sulfide $\left(\mathrm{H}_{2} \mathrm{~S}\right)$, carbon monoxide $(\mathrm{CO})$, and hydrogen $\left(\mathrm{H}_{2}\right)$. Many beverages containing hydrogen are already on the market. Paying attention to the fact that these are sold as health products, the current state of and problems with molecular hydrogen are described below [19].

Recently, the Nippon Medical School Group initially reported a treatment effect of hydrogen molecules on cerebral ischemia [20], and this has come to be expected as a new treatment method. Hydrogen has been applied to diverse disease models in various forms over the last several years, and studies on its treatment effects are rapidly progressing. While the effect of hydrogen is being scientifically elucidated, many hydrogen-containing beverages and health products are already on the market, as described above, and some products have a poor scientific basis and their effects are questionable. Moreover, the terms and definitions, such as active hydrogen-rich water, negative hydrogen ion water, reduced water, and natural hydrogen-rich water, are likely to cause misunderstanding and confusion $[3,21]$. Since commercial utilization of hydrogen started before sufficient scientific explanation and systematic analysis of the effect, it became a target of prejudice as products lacking a basis among well-informed people $[3,21]$.

However, reduction of oxidative stress was observed as an effect of hydrogen in animal experiments and clinical studies in common, and the effect was internationally reported by several independent research facilities, suggesting that the effect is an unquestionable fact. To clinically apply hydrogen, it is essential to perform systematic clinical studies, and studies have been initiated or investigated by universities and research institutions in Japan and other countries [3,21].

Kajiyama et al. reported a randomized double-blind study involving NIDDM patients, in which subjects ingested $900 \mathrm{~mL}$ of hydrogen-rich water daily for 2 months, and impaired glucose tolerance was improved [22]. Nakao et al. reported that when 20 male and female pre-metabolic syndrome patients with mild obesity, dyslipidemia, impaired glucose tolerance, and hypertension ingested 1,500-2,000 $\mathrm{mL}$ of hydrogen-rich water daily for 8 weeks, HDL cholesterol and antioxidative enzyme SOD increased [23]. They also reported a cooperative study with a Korean group, in which 25 patients being treated with radiotherapy for liver malignant tumor ingested hydrogen-rich water or placebo daily, and it significantly remitted adverse events, such as digestive symptoms and fatigue [24].

Although the mechanism of the effect on radiation damage is unclear, since oxidative stress markers in blood significantly decreased, there is no doubt that some oxidative stress induced by radiation was reduced by ingestion of hydrogen-rich water. The achievement of this study came to be known by the United States Aeronautics and Space Administration, and application of hydrogen to protect astronauts from radioactivity in space is being investigated [25].
The effect of hydrogen has been clarified in not only animal experiments but also humans, as described above, and a new page based on science has begun [21]. However, many questions and unsolved problems remain, such as whether or not the effect can be explained by removal of ROS alone, comparison with other antioxidative substances including vitamins $\mathrm{C}$ and $\mathrm{E}$ and differences in the chemical properties, and elucidation of unique characteristics as an ultra-low-molecularweight compound. There are some reports about the diseases for which various preventive and treatment effects of hydrogen were reported in clinical studies (dialysis, cystitis, myositis [26], fatigue [27], Parkinson's disease [28], Rheumatoid Arthritis [29]).

Accordingly, to aim at appropriate clinical application of hydrogen, systematic clinical studies and elucidation of the mechanism in detail are essential [21].

\section{Current State of and Problems with Oxidative Stress Markers}

It is often said that 'no evaluation can be made without measurement'

Understanding of the pathophysiology of oxidative stress and the defense mechanism against it, and accurate non- or low-invasive quantitative measurement of the oxidative stress level in patients are very important and significant for evaluation of oxidative stress at clinical sites.

Advantages of biological marker measurement are as follows:

1. The prognosis and treatment can be non- or low-invasively evaluated,

2. The pathology can be analyzed based on biological responses,

3. Measurement using similar markers is possible in animal models, and

4. Rapid testing can be clinically applied. Appropriate ascertainment of medical care may be important [30].

The currently known in vivo actions of reactive oxygen and oxidative stress markers are presented in Figure 3. Several oxidative stress markers recently attracting attention are reviewed below [4].

\section{Biopyrrin}

Since bilirubin causes nuclear icterus-associated nerve damage when its level in blood increases, it was previously considered to be a toxic or useless substance. However, it is now considered to have a reactive oxygen-scavenging action based on reports on its in vitro antioxidative effect [31]. The presence of oxidation products of bilirubin in urine and blood has been clarified, and these metabolites are tripyrrole substances, termed biopyrrin. Accordingly, this antioxidative action of bilirubin, i.e., an oxidative stress state, can be estimated by measuring biopyrrin using ELISA [32].

Elevation of the urinary level after surgery [33], mental stress [34] and coronary spastic angina has been observed [35].

\section{8-Deoxy-2-deoxyguanidne (8-OHdG)}

Reactive oxygen reacts with the guanine residue of DNA and produces $8-\mathrm{OHdG}$, and this $8-\mathrm{OHdG}$ serves as a biological marker of oxidative damage of DNA [36]. It has been reported that the urinary marker level was useful to monitor the effects of radiotherapy and chemotherapy in lung cancer patients [37], and the urinary level rose representing metal stress [38]. Yoshino et al. reported that rosuvastatin reduces the urinary 8 -OHdG level [39]. 


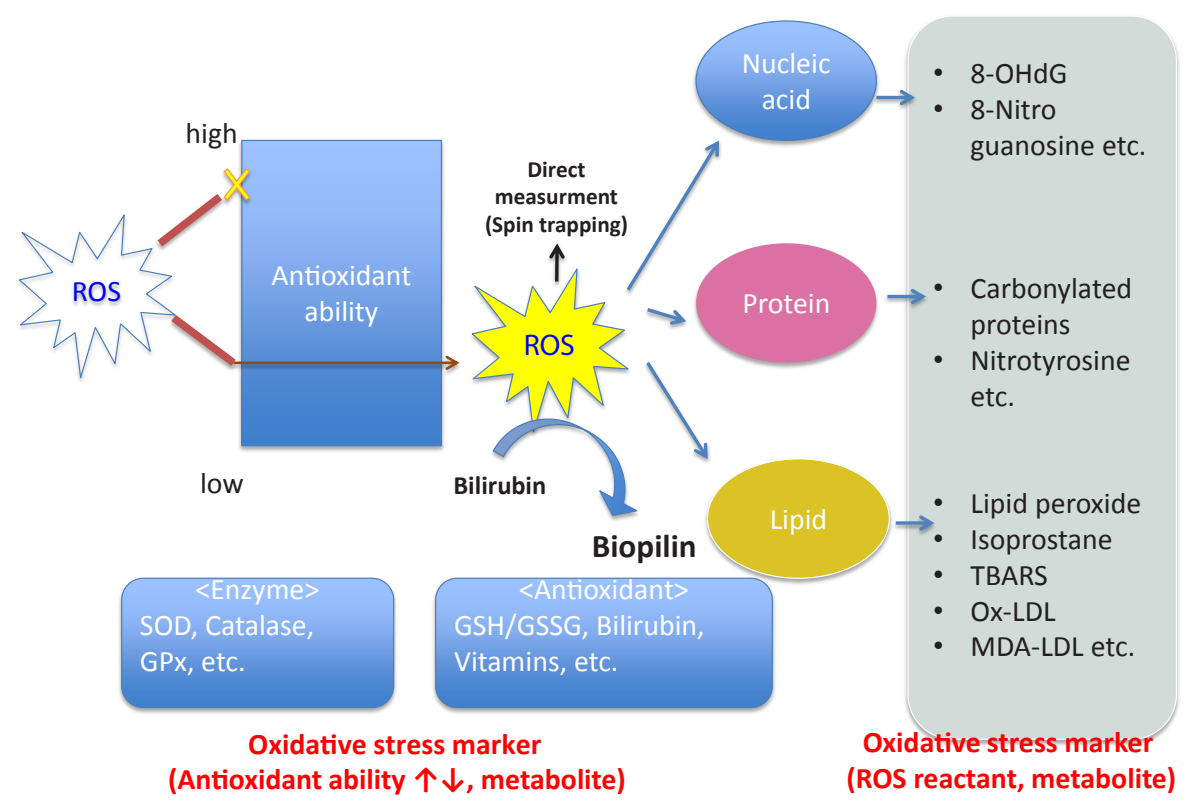

Figure 3: Various oxidative stress markers in human body.

\section{Isoprostanea F2 -III}

Isoprostanea F2 -III is non-enzymatically produced from blood LDL and cell surface phospholipid by direct oxidation of arachidonic acid by free radials [40]. A very high correlation between the grades of cytotoxicity and lipoperoxidation and blood level of this substance has been reported, and it is attracting attention as a new oxidative stress marker [41].

Elevation of this marker level in hypercholesterolemia [42], cigarette smoking [43], and diabetes [44] has been reporteda. The presence of isoprostane F2 -III in arteriosclerotic lesions in humans has also been reported [45], suggesting that this marker may serve as an index of clinical progression of arteriosclerosis.

\section{Oxidized LDL}

Oxidized LDL has been reported to play the central role in the development and progression of arteriosclerosis [46]. Toshima et al. reported that oxidized LDL increased in diabetes patients, and the level was higher in coronary arteritis patients, but no difference was noted between those with and without concomitant diabetes [47]. Elevation of the blood oxidized LDL level in patients with acute coronary syndrome, patients after percutaneous transluminal coronary angioplasty (PCI), and patients with cervical arteriosclerosis, stroke, and Alzheimer's disease has also been reported [48].

\section{MDA-LDL}

MDA-LDL is a part of oxidized LDL. When it is oxidized to the lysine residue in the protein region, it causes foaming of the vascular wall. This is an important oxidative stress marker to predict the prognosis of coronary arterial disease in diabetes patients with a past medical history of coronary arterial disease, and the prognosis concerning re-stenosis after PCI in diabetes patients [49].

Measurement and evaluation of oxidative stress using various approaches and methods are progressing, and low-cost, simple, and reliable methods will be awaited at clinical sites.

\section{Antioxidative Therapy and Immunity}

Oxidative stress is produced when the balance between the production and removal systems of active oxygen species is destroyed and the production system becomes dominant, and it causes various organ disorders. In antioxidative therapy, oxidative stress involved in diseases is reduced by capturing and stabilizing active oxygen species.

Recent studies have shown that close involvement of antioxidative therapy in immune responses (Figure 4) in the body is clarified [5052]. Antioxidants, such as many vitamins, glutathione, and $\beta$-carotene, have been reported to exhibit not only an antioxidative action but also an immune function-improving effect [51-56]. These antioxidants are also known to be useful to treat autoimmune diseases [57,58], such as rheumatoid arthritis, and further clinical application is expected.

Nutrients necessary for the normal function of immunity include essential amino acids, fatty acids, vitamin A, folic acid, vitamins B6, B12, C, and E, copper, iron, zinc, and selenium [51-56]. A lack of one or more of these nutrients reduces immunity, and the addition of lacking nutrients improves the immune function in animals and humans [51-52].

Of these with an antioxidative action, vitamin B6 promotes lymphocyte proliferation [59], vitamin C exhibits a bactericidal effect, improves NK cell activity, and promotes proliferation and chemotaxis of lymphocytes [60-62], vitamin A improves the lymphocyte function [63], and vitamin E promotes lymphocyte proliferation and improves NK cell and macrophage activities [64].

Antioxidative therapy is considered clinically useful to treat impairment and hypofunction of cells in inflammatory and autoimmune diseases, and it is clinically applied to treat rheumatoid arthritis. The usefulness of antioxidative therapy as adjuvant therapy has been reported [57,58].

In addition to the usefulness for the immune function, antioxidative therapy has recently been frequently reported to be useful for severe 


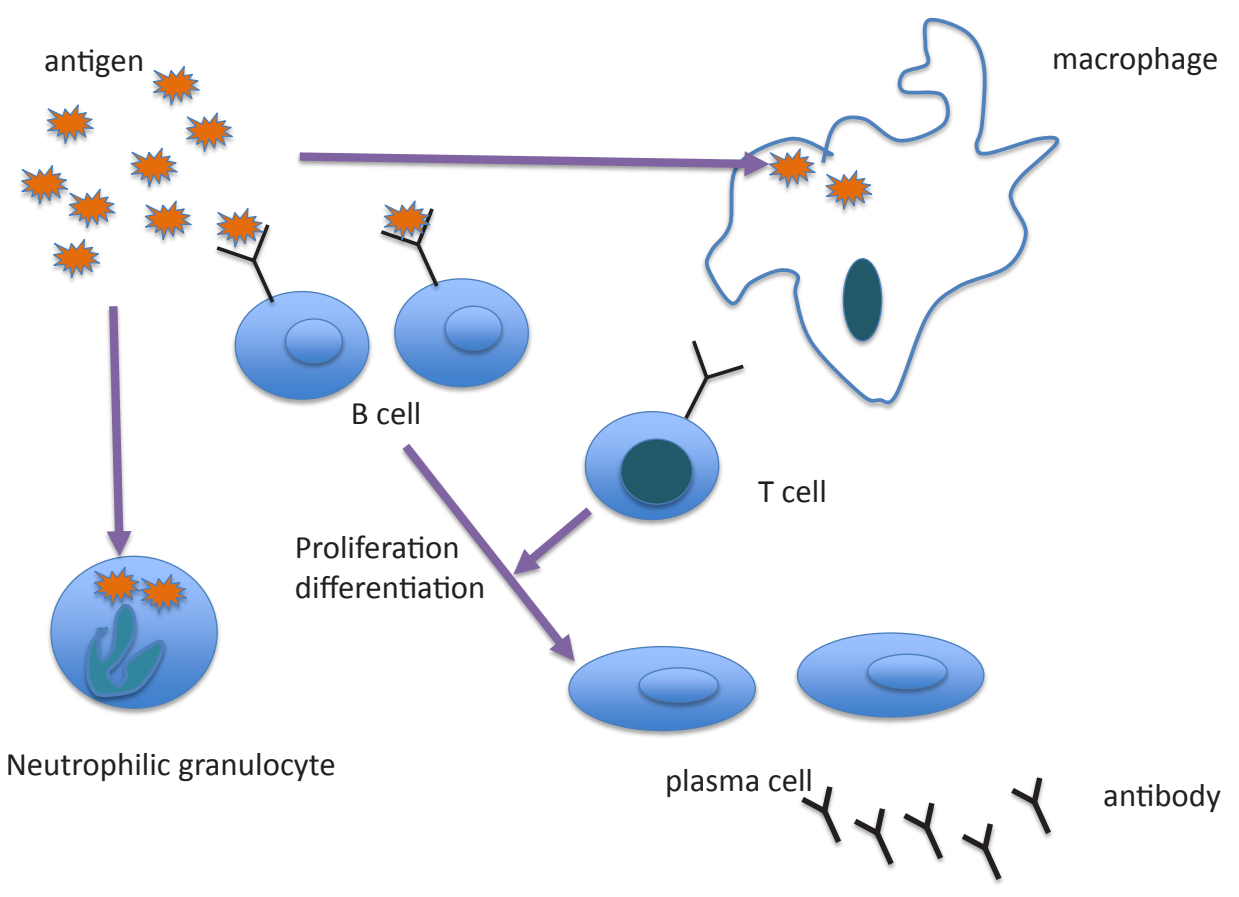

Figure 4: Immune responses in human body [5].

cases: Administration of several vitamins decreased the incidences of lung injury and multiple organ failure, and shortened the duration of artificial respiration management and ICU stay in severe trauma patients [65]. The effectiveness of trace minerals for severe burn patients with regard to the prevalence of pneumonia has also been reported [66]. Regarding the effect of a combination of trace elements and vitamins, Heyland et al. reported that antioxidant administration significantly reduced the mortality rate on meta-analysis of patients in a severe state, such as those with multiple traumas, head trauma, SIRS, burns, and postoperative ICU [67-69].

\section{Possibility of clinical application of reactive oxygen measurement in cells collected from human blood}

The bactericidal effect and induction of inflammation by reactive oxygen produced by granulocytes are known as the immune function, there are some reports about pathophysiology of each organ (lung [70-75], cardiovascular [76-78], kidney [79,80], liver [81], etc.) and evaluation of treatment (drug [79-93], food factor [94], operation [95], etc.) by radical oxygen measurement of neutrophilic granulocyte from human blood samples. But there are few reports about evaluation or investigation of clinical applications toward innovative diagnosis or preventive medicine by clinical trials.

Although it was a pilot study, Ichiishi et al. isolated granulocytes from blood samples collected in a hospital or at bedside, and measured reactive oxygen, and they reported its practicality for preventive medicine and medical care at clinical sites [6].

Blood was collected in the off-season of pollinosis from 30 volunteers comprised of 17 patients diagnosed with cedar pollinosis and 13 healthy subjects. Granulocytes were stimulated with cedar antigen, and reactive oxygen was measured using the ESR spin trapping method. A significant correlation was observed between the clinical severity classification and reactive oxygen level (Figure 5). They stated that although it was a pilot study with a small number of cases, the severity of pollinosis in the off-season may be predicted, enabling taking countermeasures and treatment from the off-season [6]. They also mentioned unpublished data: When blood granulocytes collected from 3 pneumonia patients with different clinical courses were stimulated, different reactions were observed in reactive oxygen measurement, suggesting a new functional evaluation by reactive oxygen measurement for clinical evaluation, which was previously performed mainly based on the white blood cell count (granulocyte count), proposing a possibility leading to new evaluation and step to choice appropriate therapy and prevention of refractory pneumonia and pneumonia in the elderly (data unpublished).

Evaluation of the function of cells collected from patients may be clinically significant, as described above, and reactive oxygen measurement may be useful as one of the functional evaluation tools of innovative diagnosis or preventive medicine.

\section{Others}

In regeneration and transplantation medical care, clinical application of vascular endothelial precursor cells (EPC) targeting myocardial infarction and lower limb ischemic disease is in the spotlight, but inhibition of EPC migration from the bone marrow and the properties of cells contributing to vascularization under oxidative stress and a chronic inflammatory state have been reported [96,97]. Masuda et al. [96] reported that inhibition of production and removal of reactive oxygen using oxidative stress-improving drugs/factors (antioxidative therapy) improved oxidative stress and subsequently improved EPC activity, which may increase the treatment effect of regeneration and transplantation (Figure 6). 


\section{Specific IgE \\ $(\mathrm{U} / \mathrm{ml})$}

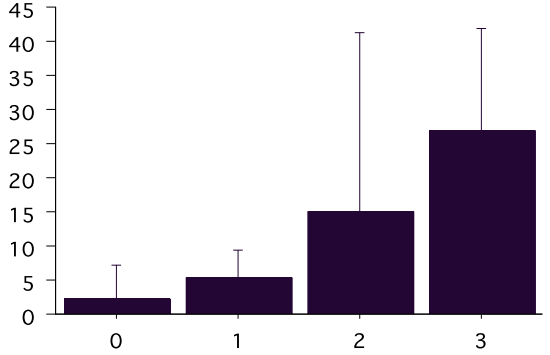

\section{Histamine release rate $(\%)$}

\section{$\mathrm{O}_{2}^{-}$generation in response to allergen}

$(\mu \mathrm{M})$

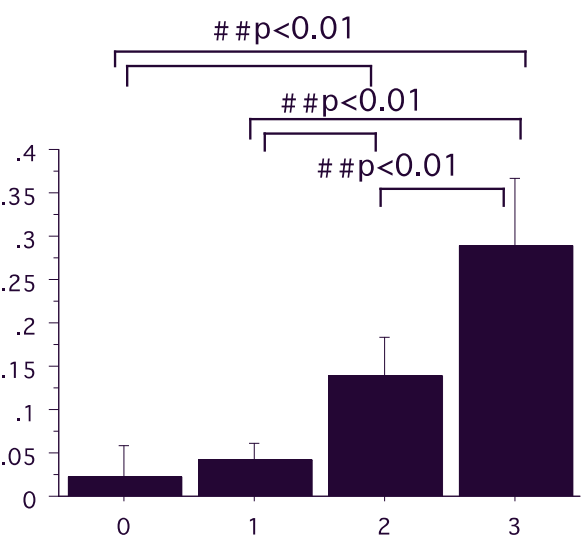

Global symptom scores in season

Figure 5: Relationships between pollinosis symptoms and specific IgE, histamine release rate, and ROS generation in response to allergen [6]

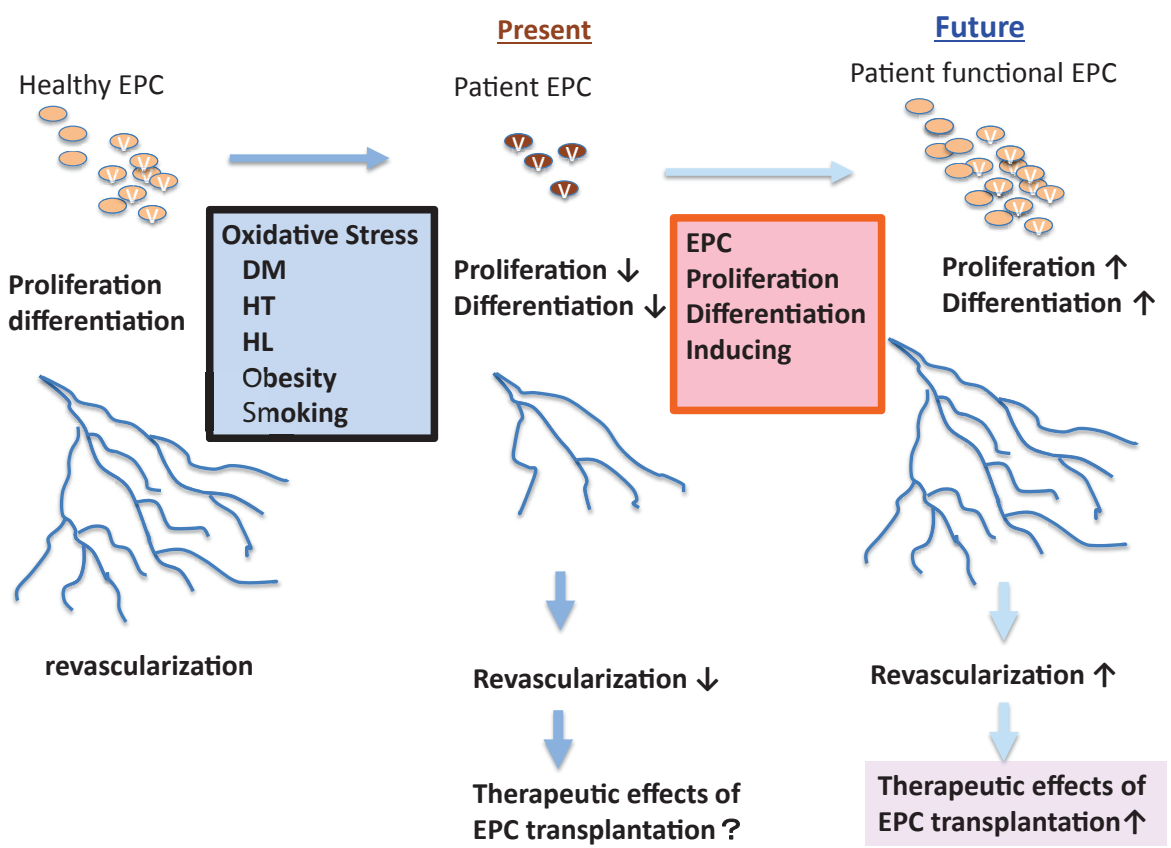

Figure 6: Current and perspective of vascular regeneration via induction of endothelial progenitor cell (EPC) expansion/differentiation [96].

\section{Conclusion}

Evaluation of oxidative stress has markedly progressed and developed in basic medicine, but there is much room left for its clinical application and development. A problem with the above development in clinical research of oxidative stress and application of the results to humans is that health foods and beverages allegedly effective for reducing oxidative stress are already on the market but more than a few of them have a poor scientific basis and their effects seem to be questionable.
This review introduces valuable studies by Japanese researchers that were reported in clinical medicine journals in Japan over the last 5-6 years.

Novelty or a focused topic may be important, but this manuscript is a review of clinical applications against oxidative stress such as those under clinical trials, and is not an original article or focused, restricted one. In this manuscript, I would like to highlight the expansion of clinical applications against oxidative stress in a wide range of fields in Japan.

There may be many excellent reviews that should be consulted and 
discussed in the world. However, all papers in my review were presented in clinical medicine journals in Japan, showing highly promising clinical applications in their Discussion sections. Indeed, most of these applications are being evaluated in clinical trials, attracting much attention in Japan. My manuscript may not include all clinical applications against oxidative stress, but includes major contents that have been recently attracting attention and expected to be clinically applied. A more comprehensive review without restriction to only Japanese data might provide a more informed overview on the topic.

These application cases naturally differ from those in the other countries. Independent development, locality, and trends in each region are sometimes desired. If the world looks in only in one direction in the same scope, originality or future development in new fields cannot be expected.

This report introduced the recent trend including these, but unquestionable bases and evidence of oxidative stress have already been accumulated in the basic study field. I hope these will be actively applied in the clinical field, accumulate evidence through performing systematic clinical studies and trials, and actually facilitate health promotion, disease prevention, and treatment effects in humans, making great contributions to actual medical practice.

\section{Disclosure Statements}

The authors declare no competing financial interests.

\section{References}

1. Olinski R, Siomek A, Rozalski R, Gackowski D, Foksinski M, et al. (2007) Oxidative damage to DNA and antioxidant status in aging and age-related diseases. Acta Biochem Pol 54: 11-26.

2. Izumi Y, Akaike A (2013) Identification of Nfr2-ARE activator from foods and the possibility for clinical applications. Igaku no Ayumi 246: 263-264.

3. Nakao A (2011) Hydrogen as a therapeutic agent for clinical applications. JMA 4548: 86-91.

4. Yoshino G (2010) Oxidative stress markers. The Lipid 21: 43-51.

5. Uchiyama K, Naito Y, Yoshikawa T (2010) Antioxidant therapy and immune system. J Funct Foods 4: 56-60.

6. Ichiishi E, Tada M, Ohta Y, Sami M, Kanda T, et al. (2015) Genomic approaches and oxygen radical measurement as biomarker candidates of off-season predictor of pollinosis.: A pilot study. Curr Pharmacogenomics Personalized Med 13: 41-50

7. Joshipura KJ, Ascherio A, Manson JE, Stampfer MJ, Rimm EB, et al.(1999) Fruit and vegetable intake in relation to risk of ischemic stroke. JAMA 282 1233-1239.

8. Izumi Y, Matsumura A, Wakita S, Akagi K, Fukuda H, et al. (2012) Isolation, identification, and biological evaluation of Nrf2-ARE activator from the leave of green perilla (Perilla frutescens var. crispa f. viridis). Free Radic Biol Med 53: $669-679$.

9. Thimmulappa RK, Fuchs RJ, Malhotra D, Scollick C, Traore K, et al. (2007) Preclinical evaluation of targeting the Nrf2 pathway by triterpenoids (CDDO-Im and CDDO-Me) for protection from LPS-induced inflammatory response and reactive oxygen species in human peripheral blood mononuclear cells and neutrophils. Antioxid Redox Signal 9: 1963-1970.

10. Pergola PE, Raskin P, Toto RD, Meyer CJ, Huff JW, et al. (2011) Bardoxolone methyl and kidney function in CKD with type 2 diabetes. N Engl J Med 365: 327-36.

11. de Zeeuw D, Akizawa T, Agarwal R, Audhya P, Bakris GL, et al. (2013) Rationale and trial design of Bardoxolone Methyl Evaluation in Patients with Chronic Kidney Disease and Type 2 Diabetes: the Occurrence of Renal Events (BEACON). Am J Nephrol 37: 212-22.

12. Kurokawa $H$ (2013) Structure relationship of Keap1 as chemical sensor. The Journal of Japanese Biochemical Society 85: 663-670.
13. Lee JS, Surh YJ (2005) Nrf2 as a novel molecular target for chemoprevention. Cancer Lett 224: 171-184.

14. Jeong WS, Keum YS, Chen C, Jain MR, Shen G, et al. (2005) Differentia expression and stability of endogenous nuclear factor E2-related factor 2 (Nrf2) by natural chemopreventive compounds in HepG2 human hepatoma cells. J Biochem Mol Biol 38: 167-176.

15. Murakami A, Ashida H, Terao J (2008) Multitargeted cancer prevention by quercetin. Cancer Lett 269: 315-25.

16. Itoh K, Mochizuki M, Ishii Y, Ishii T, Shibata T, et al. (2004) Transcription factor Nrf2 regulates inflammation by mediating the effect of 15-deoxy-Delta $(12,14)$ prostaglandin. Mol Cell Biol 24: 36-45.

17. Sawa T, Zaki MH, Okamoto T, Akuta T, Tokutomi $Y$, et al (2007) Protein S-guanylation by the biological signal 8-nitroguanosine 3',5'-cyclic monophosphate. Nat Chem Biol 3: 727-735.

18. Dietz BM, Kang YH, Liu G, Eggler AL, Yao P, et al. (2005) Xanthohumol isolated from Humulus lupulus Inhibits menadione-induced DNA damage through induction of quinone reductase. Chem Res Toxicol 18: 1296-1305.

19. Nakao A, Kotani J (2013) Application of therapeutic signaling gas for acute lung injury. Journal of Japanese Association for Acute Medicine 24: 59-68.

20. Ohsawa I, Ishikawa M, Takahashi K, Watanabe M, Nishimaki K, et al. (2007) Hydrogen acts as a therapeutic antioxidant by selectively reducing cytotoxic oxygen radicals. Nat Med 13: 688-694.

21. Huang CS, Kawamura T, Toyoda Y, Nakao A (2010) Recent advances in hydrogen research as a therapeutic medical gas. Free Radic Res 44: 971-982.

22. Kajiyama S, Hasegawa G, Asano M, Hosoda H, Fukui M, et al. (2008) Supplementation of hydrogen-rich water improves lipid and glucose metabolism in patients with type 2 diabetes or impaired glucose tolerance. Nutr Res 28 : 137-143.

23. Nakao A, Toyoda Y, Sharma P, Evans M, Guthrie N (2010) Effectiveness of hydrogen rich water on antioxidant status of subjects with potential metabolic syndrome-an open label pilot study. J Clin Biochem Nutr 46: 140-149.

24. Kang KM, Kang YN, Choi IB, Gu Y, Kawamura T, et al. (2011) Effects of drinking hydrogen-rich water on the quality of life of patients treated with radiotherapy for liver tumors. Med Gas Res 1: 11.

25. Schoenfeld MP, Ansari RR, Zakrajsek JF, Billiar TR, Toyoda Y, et al. (2011) Hydrogen therapy may reduce the risks related to radiation-induced oxidative stress in space flight. Med Hypotheses 76: 117-118.

26. Ohta S (2014) Molecular hydrogen as a preventive and therapeutic medica gas: initiation, development and potential of hydrogen medicine. Pharmacol Ther 144: 1-11.

27. Aoki K, Nakao A, Adachi T, Matsui Y, Miyakawa S (2012) Pilot study: Effects of drinking hydrogen-rich water on muscle fatigue caused by acute exercise in elite athletes. Med Gas Res 2: 12

28. Yoritaka A, Takanashi M, Hirayama M, Nakahara T, Ohta S, et al. (2013) Pilot study of $\mathrm{H}$ therapy in Parkinson's disease: a randomized double-blind placebocontrolled trial. Mov Disord 28: 836-839.

29. Ishibashi T, Sato B, Shibata S, Sakai T, Hara Y, et al. (2014) Therapeutic efficacy of infused molecular hydrogen in saline on rheumatoid arthritis: a randomized, double-blind, placebo-controlled pilot study. Int Immunopharmacol 21: 468-473.

30. Tsukahara H (2007) Biomarkers for oxidative stress: clinical application in pediatric medicine. Curr Med Chem 14: 339-351.

31. Stocker R, Yamamoto Y, McDonagh AF, Glazer AN, Ames BN (1987) Bilirubin is an antioxidant of possible physiological importance. Science 235: 1043-1046.

32. Yamaguchi T, Shioji I, Sugimoto A, Komoda Y, Nakajima H (1994) Chemical structure of a new family of bile pigments from human urine. J Biochem 116 298-303.

33. Kozaki N, Shimizu S, Chijiwa K, Yamaguchi K, Kuroki S, et al. (1999) Bilirubin as an anti-oxidant for surgical stress: a preliminary report of bilirubin oxidative metabolites. HPB Surg 11: 241-248.

34. Yamaguchi T, Shioji I, Sugimoto A, Yamaoka M (2002) Psychological stress increase bilirubin metabolites in human urine. Biochem Biophys Res Commun 293: 517-520. 
Citation: Ichiishi E, Ohtake T, Satoh K, Kohgo Y (2016) Oxidative Stress and Diseases: Current Topics and Perspective with Clinical Application in Japan. Aging Sci 4: 161. doi: 10.4172/2329-8847.1000161

35. Morita Y, Takahashi H, Kamihata H, Yamamoto Y, Hara K, et al. (2001). Urinary excretion of biopyrrins, oxidative metabolites of bilirubin, increases after spasm provocation tests in patients with coronary spastic angina. Int $\mathrm{J}$ Cardiol 80: 243-250.

36. Valavanidis A, Vlachogianni T, Fiotakis C (2009) 8-hydroxy-2' -deoxyguanosine (8-OHdG): A critical biomarker of oxidative stress and carcinogenesis. J Environ Sci Health C Environ Carcinog Ecotoxicol Rev 27: 120-139

37. Erhola M, Toyokuni S, Okada K, Tanaka T, Hiai H, et al. (1997) Biomarker evidence of DNA oxidation in lung cancer patients: association of urinary 8-hydroxy-2'-deoxyguanosine excretion with radiotherapy, chemotherapy, and response to treatment. FEBS Lett 409: 287-291.

38. Adachi S, Kawamura K, Takemoto K (1993) Oxidative damage of nuclear DNA in liver of rats exposed to psychological stress. Cancer Res 53: 4153-4155.

39. Yoshino G, Tanaka M, Nakano S, Matsumoto T, Kojima M, et al. (2009) Effect of rosuvastatin on concentrations of plasma lipids, urine and plasma oxidative stress markers, and plasma high-sensitivity C-reactive protein in hypercholesterolemic patients with and without type 2 diabetes mellitus: A 12week, open-label, pilot study. Curr Ther Res Clin Exp 70: 439-448.

40. Patrono C, FitzGerald GA (1997) Isoprostanes: potential markers of oxidan stress in atherothrombotic disease. Arterioscler Thromb Vasc Biol 17: 23092315.

41. Praticò D, Barry OP, Lawson JA, Adiyaman M, Hwang SW, et al. (1998) IPF2alpha-I: an index of lipid peroxidation in humans. Proc Natl Acad Sci USA 95: 3449-3454

42. Reilly MP, Praticò D, Delanty N, DiMinno G, Tremoli E, et al. (1998) Increased formation of distinct F2 isoprostanes in hypercholesterolemia. Circulation 98 2822-2828.

43. Ohashi N, Yoshikawa M (2000) Rapid and sensitive quantification of 8-isoprostaglandin F2 $\alpha$ in human plasma and urine by liquid chromatographyelectrospray ionization mass spectrometry. J Chromatogr B Biomed Sci App 746: $17-24$.

44. Davì G, Ciabattoni G, Consoli $A$, Mezzetti $A$, Falco A, et al. (1999) In vivo formation of 8-iso-prostaglandin f2alpha and platelet activation in diabetes mellitus: effects of improved metabolic control and vitamin E supplementation. Circulation 99: 224-229.

45. Praticò D, luliano L, Mauriello A, Spagnoli L, Lawson JA, et al. (1997) Localization of distinct F2-isoprostanes in human atherosclerotic lesions. J Clin Invest 100: 2028-2034

46. Steinbrecher UP, Parthasarathy S, Leake DS, Witztum JL, Steinberg D (1984) Modification of low density lipoprotein by endothelial cells involves lipid peroxidation and degradation of low density lipoprotein phospholipids. Proc Natl Acad Sci USA 81: 3883-3887.

47. Toshima S, Hasegawa A, Kurabayashi M, Itabe H, Takano T, et al. (2000) Circulating oxidized low density lipoprotein levels. A biochemical risk marker for coronary heart disease. Arterioscler Thromb Vasc Biol 20: 2243-2247.

48. Fraley AE, Tsimikas S (2006) Clinical applications of circulating oxidized lowdensity lipoprotein biomarkers in cardiovascular disease. Curr Opin Lipidol 17: 502-509.

49. Shigematsu S, Takahashi N, Hara M, Yoshimatsu H, Saikawa T (2007) Increased incidence of coronary in-stent restenosis in type 2 diabetic patients is related to elevated serum malondialdehyde-modified low-density lipoprotein. Circ J 71:1697-702.

50. Gross RL, Newberne PM (1980) Role of nutrition in immunologic function Physiol Rev 60: 188-302.

51. Chandra RK (1991) 1990 McCollum Award lecture. Nutrition and immunity: lessons from the past and new insights into the future. Am J Clin Nutr 53: 1087 1101.

52. Scrimshaw NS, SanGiovanni JP(1997) Synergism of nutrition, infection, and immunity: an overview. Am J Clin Nutr 66: 464S-477S.

53. Calder PC, Jackson AA (2000) Undernutrition, infection and immune function. Nutr Res Rev 13: 3-29.

54. De la Fuente M, Victor VM (2000) Anti-oxidants as modulators of immune function. Immunol Cell Biol 78: 49-54.

55. Correa R, Blanco B, Del Río M, Víctor V, Guayerbas N, et al. (1999) Effect of a diet supplemented with thioproline on murine macrophage function in a mode of premature ageing. Biofactors 10: 195-200.
56. Katsuura S, Imamura T, Bando N, Yamanishi R (2009) beta-Carotene and betacryptoxanthin but not lutein evoke redox and immune changes in RAW264 murine macrophages. Mol Nutr Food Res 53: 1396-1405.

57. van Vugt RM, Rijken PJ, Rietveld AG, van Vugt AC, Dijkmans BA (2008) Antioxidant intervention in rheumatoid arthritis: results of an open pilot study. Clin Rheumatol 27: 771-775

58. Helmy M, Shohayeb M, Helmy MH, el-Bassiouni EA (2001) Antioxidants as adjuvant therapy in rheumatoid disease. A preliminary study. Arzneimittelforschung 51: 293-298.

59. Kwak HK, Hansen CM, Leklem JE, Hardin K, Shultz TD (2002) Improved vitamin B-6 status is positively related to lymphocyte proliferation in young women consuming a controlled diet. J Nutr 132: 3308-3313.

60. Haskell BE, Johnston CS (1991) Complement component C1q activity and ascorbic acid nutriture in guinea pigs. Am J Clin Nutr 54: 1228S-1230S.

61. Jacob RA, Kelley DS, Pianalto FS, Swendseid ME, Henning SM, et al. (1991) Immunocompetence and oxidant defense during ascorbate depletion of healthy men. Am J Clin Nutr. 1991;54(6 Suppl):1302S-1309S.

62. Panush RS, Delafuente JC, Katz P, Johnson J (1982) Modulation of certain immunologic responses by vitamin C. III. Potentiation of in vitro and in vivo lymphocyte responses. Int J Vitam Nutr Res Suppl 23: 35-47.

63. Rahman MM, Mahalanabis D, Alvarez JO, Wahed MA, Islam MA, et al. (1997) Effect of early vitamin A supplementation on cell-mediated immunity in infants younger than 6 mo. Am J Clin Nutr 65: 144-148.

64. Meydani SN, Han SN, Wu D (2005) Vitamin E and immune response in the aged: molecular mechanisms and clinical implications. Immunol Rev 205: 269

65. Nathens AB, Neff MJ, Jurkovich GJ, Klotz P, Farver K, et al. (2002) Randomized, prospective trial of antioxidant supplementation in critically ill surgical patients. Ann Surg 236: 814-822.

66. Berger MM, Eggimann P, Heyland DK, Chioléro RL, Revelly JP, et al. (2006) Reduction of nosocomial pneumonia after major burns by trace element supplementation: aggregation of two randomised trials. Crit Care 10: R153.

67. Heyland DK, Dhaliwal R, Suchner U, Berger MM (2005) Antioxidant nutrients: a systematic review of trace elements and vitamins in the critically ill patient. Intensive Care Med 31: 327-337.

68. Heyland DK, Dhaliwal R, Day AG, Muscedere J, Drover J, et al. (2006) Reducing Deaths due to OXidative Stress (The REDOXS Study): Rationale and study design for a randomized trial of glutamine and antioxidant supplementation in critically-ill patients. Proc Nutr Soc 65: 250-263.

69. Jones NE, Heyland DK (2008) Pharmaconutrition: a new emerging paradigm Curr Opin Gastroenterol 24: 215-222.

70. van Helvoort HA, Heijdra YF, Heunks LM, Meijer PL, Ruitenbeek W, et al (2006) Supplemental oxygen prevents exercise-induced oxidative stress in muscle-wasted patients with chronic obstructive pulmonary disease. Am J Respir Crit Care Med 173: 1122-1129.

71. van Helvoort HA, Heijdra YF, de Boer RC, Swinkels A, Thijs HM, et al. (2007) Six-minute walking-induced systemic inflammation and oxidative stress in muscle-wasted COPD patients. Chest 131: 439-445.

72. Wehlin L, Löfdahl M, Lundahl J, Sköld M (2005) Reduced intracellular oxygen radical production in whole blood leukocytes from COPD patients and asymptomatic smokers. Chest 128: 2051-2058.

73. Lukas R, Schärling B, Schultze-Werninghaus G, Gillissen A (2005) Antioxidan treatment with $\mathrm{N}$-acetylcysteine and vitamin $\mathrm{C}$ in patients with chronic bronchitis. Dtsch Med Wochenschr 130: 563-567.

74. Simbirtsev A, Variouchina E, Konusova V, Kotov A, Ketlinsky S, et al. (2001) Local administration of interleukin-1beta for the treatment of lung abscesse induces neutrophil activation and changes in proinflammation cytokine production. Eur Cytokine Netw 12: 420-429.

75. BelotskiǐSM, Karlov VA, Filiukova OB, Kuznetsov VP, Zueva VS, et al. (1990) Clinical and laboratory effect of leukinferon in purulent infections. Antibiot Khimioter 35: 36-38.

76. KalawskińM, R BugajskiBali P, Wysocki H, Olszewski R, Siminiak T (2001) Stimulation of neutrophil activation during coronary artery bypass grafting comparison of crystalloid and blood cardioplegia. Ann Thorac Surg 71: 827 831. 
Citation: Ichiishi E, Ohtake T, Satoh K, Kohgo Y (2016) Oxidative Stress and Diseases: Current Topics and Perspective with Clinical Application in Japan. Aging Sci 4: 161. doi: 10.4172/2329-8847.1000161

77. Di Salvo C, Louca LL, Pattichis K, Hooper J, Walesby RK, et al. (1996) Does activated neutrophil depletion on bypass by leukocyte filtration reduce myocardial damage? A preliminary report. J Cardiovasc Surg (Torino) 37: 93-

78. Fabiani JN, Farah B, Vuilleminot A, Lecompte T, Emerit I, et al. (1933) Chromosomal aberrations and neutrophil activation induced by reperfusion in the ischaemic human heart. Eur Heart J 14: 12-17.

79. Ward RA, Ouseph R, McLeish KR (2003) Effects of high-flux hemodialysis on oxidant stress. Kidney Int 63: 353-359.

80. Neveceral P, Markert M, Wauters JP (1995) Role of protein adsorption on haemodialysis-induced complement activation and neutrophil defects. Nephrol Dial Transplant 10: 372-376.

81. Jabłonowska E, Tchórzewski H, Lewkowicz P, Kuydowicz J (2005) Reactive oxygen intermediates and serum antioxidative system in patients with chronic $\mathrm{C}$ hepatitis treated with IFN-alpha and thymus factor X. Arch Immunol Ther Exp (Warsz) 53: 529-533.

82. Zilberstein G, Levy R, Rachinsky M, Fisher A, Greemberg L, et al. (2002) Ketamine attenuates neutrophil activation after cardiopulmonary bypass. Anesth Analg 95: 531-536.

83. Weiss T, Eckstein H, Weiss C, Diehm C (1998) Neutrophil function in peripheral arterial occlusive disease: the effects of prostaglandin E1. Vasc Med 3: 171175.

84. Bozdayi M, Borowiec J, Nilsson L, Venge P, Thelin S (1996) Effects of heparin coating of cardiopulmonary bypass circuits on in vitro oxygen free radical production during coronary bypass surgery. Artif Organs. 20: 1008-1016.

85. Herbńskaczy-Cedro K, Klosiewicz-Wasek B, Cedro K, Wasek W, PanczenkoKresowska B, et al. (1995) Supplementation with vitamins $C$ and $E$ suppresses leukocyte oxygen free radical production in patients with myocardial infarction. Eur Heart J 16: 1044-1049.

86. Wysocki H, Siminiak T, Zozulińska D, Wierusz-Wysocka B (1995) Evaluation of the effect of oral enalapril on neutrophil functions: comparison with the in vitro effect of enalapril and enalaprilat. Pol J Pharmacol 47: 53-58.
87. Jarstrand C, Akerlund B (1994) Oxygen radical release by neutrophils of HIV infected patients. Chem Biol Interact 91: 141-146.

88. Wiedermann CJ, Sitte B, Zilian U, Reinisch N, Beimpold H, et al. (1992) Inhibition of superoxide anion release from circulating neutrophils by L-arginine in man. Clin Investig 71: 985-989.

89. Darius H, Grodzinska L, Meyer J (1992) The effects of the nitric oxide donors molsidomine and IN-I on human polymorphonuclear leucocyte function in vitro and ex vivo. Eur J Clin Pharmacol 43: 629-633.

90. Ristola M, Savilahti E, Leirisalo-Repo M, Repo H (1991) Increased whole blood chemiluminescence in patients with Shwachman syndrome: therapy trial with thiamine and alpha-tocopherol. Eur J Pediatr 150: 173-178.

91. Suzuki M, Mori M, Miura S, Suematsu M, Fukumura D, et al. (1996) Omeprazole attenuates oxygen-derived free radical production from human neutrophils. Free Radic Biol Med 21: 727-731.

92. Andersen LW, Thiis J, Kharazmi A, Rygg I (1995) The role of $\mathrm{N}$-acetylcystein administration on the oxidative response of neutrophils during cardiopulmonary bypass. Perfusion 10: 21-26.

93. linuma S, Naito Y, Yoshikawa T, Takahashi S, Takemura T, et al. (1998) In vitro studies indicating antioxidative properties of rebamipide. Dig Dis Sci 43: 35-39.

94. Bozonet SM, Carr AC, Pullar JM, Vissers MC (2015) Enhanced human neutrophil vitamin $\mathrm{C}$ status, chemotaxis and oxidant generation following dietary supplementation with vitamin C-rich SunGold kiwifruit. Nutrients 7: 2574-2588.

95. Sietses C, Wiezer MJ, Eijsbouts QA, van Leeuwen PA, Beelen RH, et al. (2000) The influence of laparoscopic surgery on postoperative polymorphonuclear leukocyte function. Surg Endosc 14: 812-816.

96. Masuda $\mathrm{H}$, Asahara T (2010) Perspective of vascular regeneration via induction of endothelial progenitor cell expansion/differentiation. Exp Med 28: 268-273

97. Tousoulis D, Andreou I, Antoniades C, Tentolouris C, Stefanadis C (2008) Role of inflammation and oxidative stress in endothelial progenitor cel function and mobilization: therapeutic implications for cardiovascular diseases. Atherosclerosis 201: 236-247. 